\title{
Core Competences and Optimising Bank Capital Management in Nigeria
}

\author{
Andrew O Agbada PhD \\ Accounting, Banking and Finance Department, Faculty of Management Sciences \\ Delta State University, Asaba Campus, Asaba, Delta State, Nigeria \\ Tel: 234-80-3397-0008Ｅ-mail: andrewoagbada@gmail.com \\ Deborah O Odejimi PhD \\ Department of Economics and Development Studies, College of Social Sciences \\ Igbinedion University, Okada, Edo State, Nigeria
}

Tel: 234-80-5331-1615

Received: October 6, 2012

Accepted: November 15, 2012

Online Published: December 23, 2012

doi:10.5430/ijfr.v4n1p75

URL: http://dx.doi.org/10.5430/ijfr.v4n1p75

\begin{abstract}
This study explores empirically how Core Competences predicts efficient bank capital management in the Nigerian banking industry. We adopted Competence predictors namely, knowledge, skill and attitude as our independent variables and Return on Capital Employed (ROCE), the common method of measuring the size of returns derived from capital funds as our dependent variable. The empirical evidence obtained revealed a dwindling state of employees' core competences, meaning that the necessary knowledge, skill and attitude required to efficiently manage bank capital were lacking in a good proportion of employees under investigation. Of course, the empirical results may be the reflection of the recruitment strategy that undermined professionalism in academic qualification of bank employees which has been prevalent in the industry from the 1980s and may also serve as a lesson for relevant authorities in the industry.
\end{abstract}

Keywords: Core competence, Knowledge, Skill, Attitude, Return on capital employed, Banking, Nigeria

\section{Introduction}

The emergence of diverse business innovations and strategies in modern times, coupled with the advancement in Information and Communication Technology (ICT) have introduced a wide range of complexities into businesses such that the human action is now one of the most dominant inputs to any effective, efficient and proactive performance and managerial strategy. This brought into fore the concept of core competences that has to do with the capability of employees to exceptionally perform to meet set standards as a result of some intrinsic values residing in their heads. According to Boyatzis $(1982,240)$, Competence encompasses knowledge, skills, attitude and behaviours that are causally elated to superior job performance. More generally, core competence encompasses a combination of knowledge, skills and behaviour utilised to improve performance and that enables an employee to perform efficiently. It is the state or quality of being adequately qualified, having the ability to perform a specific duty to acceptable standards. An employee is said to posses the relevant Competence as long as the skills and abilities and knowledge that constitute that Competence are part of him, enabling him to accomplish his duties efficiently within certain workplace environments. Armstrong (1991) argued that Competence in its broadest sense consists of the knowledge, skill and qualities applied by individuals to the successful achievement of their job objective.

In recent times, theoretical and empirical literatures have reinforced and emphasized the importance of Competence as an essential predictor of outstanding performance in organizations. In knowledge-based organizations such as banking institutions, targets are being set for employees and goals have to be achieved at stipulated times as an indication of being competent. Becker, (2001;1) argued that 'the most successful companies and the most successful countries will be those that manage human capital in the most effective and efficient fashion, investing in their workers, encouraging workers to invest in themselves, provide a good learning environment and yes, include social capital as well as skills and training'. 
Several reasons have been adjudged for the change from concepts and processes that were viewed as organizational performance such as Total Quality Management (TQM), Entrepreneurialism, Vertical Integration, Net-work building, Reengineering, to name a few, to Competence-based performance approach by management thinkers. Jessup (1989) opined that 'a significant pressure behind this in the UK has been the supposed lack of relevance of vocational provision and the need to compete with other economies'. Smith (1996) posits that 'the move has been heavily influenced by the development of management thinking and practice and in particular, the rise of scientific management. We can see Competence and Competences used as part of everyday language of teacher education, further education, community work, youth work and community education. It appeared to solve various problems, that of relevance, that of access, that of privilege and comparability'. Wikipedia encyclopedia sums it up this way: 'more recent research by individuals such as Daniel Goleman in 'Emotional Intelligence' and Rick Boyatzis in the 'Competent Manager' have reinforced and emphasized the importance of Competences as essential predictors of outstanding performance'. It predicts outstanding performance in leadership, management, communication, banking, technology et cetera.

The banking industry in Nigeria has undergone several policy reforms in order to restore efficient corporate performance to the sector. Prior to now, the industry witnessed mass failures of banks, distresses, re-capitalization, merger and acquisition, buy-out and bailout operations and purchases of bad loans in order to rescue ailing banks from operating on negative shareholder's funds. The uncertainty that the industry has witnessed in recent times has prompted regulators to take certain actions which include the sacking of five Managing Directors of banks in August, 2009 followed by a N620 billion CBN bailout operations in order to correct the looming danger associated with the drain on capital. This study is aimed at investigating the relationship between Competence-based predictors namely, knowledge, skill and attitude and ROCE, the measure of returns derived from the capital invested by a firm in operation. For this reason, we formulate a null hypothesis that links the dependent variable, ROCE and independent variables, knowledge, skill and attitude as follows.

Ho: There is no relationship between Return on Capital Employed (ROCE) and Knowledge, Skill and Attitude with respect to bank capital management in Nigeria.

The research study is subdivided into five broad sections. Section one contained the introduction; section two deals with the review of related literatures; section three contains research methodology, the theoretical framework and model specification; section four is the analysis of empirical results and section five is the summary, conclusions and recommendations.

\section{Review of Related Literatures}

The concept of Competence was actually pioneered by the legendary management guru Peter Druker. According to Mickletwait and Wooldridge, $(1994 ; 79)$ a great theme of Druker's work has been the replacement of the old industrial proletariat with knowledge workers. Druker spent much of his career looking at how the knowledge worker themselves can come to terms with the new world since they rather than their employers control the key productive asset (brain power) of modern society. It might be necessary to re-emphasize that in recent times, the importance of Competence as an essential predictor of outstanding performance in organizations is being reinforced and that again brings to fore the relevance of Becker's argument that the most successful companies and the most successful countries will be those that manage human capital in the most effective and efficient fashion, investing in their workers, encouraging workers to invest in themselves, provide a good learning environment and yes, include social capital as well as skills and training (Becker;2001,1)

In out quest to explain the fundamental principles of Competence, we have adopted Boyatzis's definition of Competence as a benchmark and from the underlying components of Competence given therein; we derived our independent or explanatory variables. For this noble reason, we reiterate Boyatzis's definition. Boyatzis (1982:240), defined Competence as encompassing knowledge, skills, attitude and behaviour that are causally elated to superior job performance'. For knowledge-based organizations there exists a consensus in theoretical literatures that the concept of Competence has become the hallmark and driving force behind the success of modern businesses. Lynch, (1997:258,471) affirmed that 'Core competences covers an integration of skills, knowledge and technology that enables an organization to provide a particular benefit to customers'. From these definitions, we deduce that Competences as human attributes predict efficient employee performance because they are important in the development of strategy that provide a particular value, preferences or benefit to the customers of organizations. Thus, Lynch, (1997:471) further argued that Competence enable organization to build unparalleled and unique products or render unequalled services which then form the basis of the business area of the company. It does mean that employee Competences make real impact on how the customer perceives the organization and its product or 
services. Prahalad and Hamel, (1990) wrote in their article in Harvard Business Review that core Competence is an area of specializing expertise, that is, the result of harmonizing complex streams of technology and work activities. As an example, they gave Honda's expertise in engines. Honda was able to exploit the core competences of its employee to develop a variety of quality products from lawn mowers and snow blowers to trucks and automobiles. Another example from the automotive industry is Volvo automobile company. It has been claimed that Volvo core-competency is safety. This perhaps, is the end result or attribute derived from their employee's core competences in terms of customer benefit. Their core competence is more about their ability to resource and design high protection component, or to research and respond to market demands concerning safety (Wikipedia).

Competence-based strategic management theory is aimed at explaining how organizations manage, control, coordinate and utilize their scarce resources in a systematic and structural way to achieve their objectives. Competence allows knowledge-based organizations to structurally and systematically organize, plan and commit resources for the realization of organizational goals. Consequently, Competence enables firms create and enhance customer value and preference which ultimately may lead to a company evolving an area of specialization. Sanchez, (2002:520) contends that a competent organization has the ability (being capable of) to structurally and systematically coordinate and commit resources for respectively the realization of the organizations goals and objectives and the creation and distribution of customer value in order to develop competitive advantage'. Further, Sanchez, $(2002 ; 520)$ explained that there may be a static and dynamic approach to competence-based strategic management. The focus on the static approach to Competence-based management is at entirely exploiting existing resources to develop competitive advantage in the short-term. In this case strategy means a maximum exploitation of the current organizational Competences. The primary aim of the dynamic approach of the Competence-based management is realizing competitive advantage by constantly improving the existing resources and obtaining new resources. In this case, strategy means a fit between the available resources and obtaining and developing new resources.

Raye and Walter (2003:1) viewed competence management strategies (CMS) as being designed to assist in addressing the specific needs of competent managers in their innovative work environments. Thus, in any organization, positioning the competence management system positively and effectively is important. It is important and useful to introduce competence management as a tool for career management in such areas as training and development, career progression and off course, the management of the capital of a firm which this study seeks to explore. Homer (2004:4) contends that competence assessment as a management tool, can effectively isolate employees current skill gaps and help them in mapping out training and development plans targeted at closing those gaps. For modern, effective and efficient organizations Competence is now used as a criterion to define the structure of jobs in the organization. It is used for the purpose of standardizing processes, remuneration, building an organization culture, aligning activities of people with the behavioural desires of the organization, training needs of an organization, performance measurement, development planning and capital rationing or management.

\section{Research Methods}

\subsection{Research Design and Data Analysis Techniques}

The pattern followed by the Research design is referred to as 'Survey Design' and is aimed to study our research population by selecting and studying samples chosen from the population in order to make logical inferences or judgment on the basis of circumstantial evidence. The sampling technique adopted in this study is the Random sampling technique which gives a fair view of the population under study. Our target population for this study is bank employees who are in the senior, middle and lower executive categories of eighteen randomly selected banks in Nigeria. Our sample was drawn from these banks located in Lagos and Benin City, Nigeria. A sample size of five hundred and forty bank employees was derived by random distribution of thirty questionnaires to employees of each of the eighteen banks selected as our target population.

The major research instrument used in the conduct of the study was questionnaires which were administered randomly on our sample population. The questions were designed to show that employee's Knowledge is an essential pre-requisite for bank capital management and effective performance, to analyze how Skill impacts on Return on Capital Employed (ROCE) and to examine how a winning Attitude is a recipe for managerial effectiveness in the banking Industry. The questionnaire has two sections: Section A tagged 'Demographic Section' contains the personal data of respondents, basically to enable us determine the level of experience and education, and Section B contains the questions and answer options. The answer options on the questionnaire which ranges from 'Strongly disagree, Disagree, Uncertain, Agree to Strongly agree' were weighted 1,2,3,4, and 5, respectively. Individual respondent weighted scores for each of the competence-based variables were summed up to arrive at the respondent score. The 
'mean score' for all the respondents in a bank were obtained as the score of that bank for each variable. This way, we measured competence-based predictor's variables. The data obtained for Competence-based variables; Knowledge Skill and Attitude are shown in Table 1 below. Data on Return on capital Employed (ROCE) of our eighteen selected banks were obtained from their Annual Reports. The obtained data were analyzed using Correlation and Multiple Regression techniques. In estimating our data for analysis, we used the Statistical Package for Social Science, (SPSS), Version 16.0 for Windows.

\subsection{Theoretical Framework and Model Specification}

The general research model for our empirical estimation is given as:

$$
\mathrm{Y}=\mathrm{f}\left(\mathrm{X}_{1}, \mathrm{X}_{2}, \mathrm{X}_{3}\right)
$$

Where:

$$
\mathrm{Y}=\text { Return on Capital Employed (ROCE) and }
$$

$$
\mathrm{X}_{1} ; \mathrm{X}_{2} ; \mathrm{X}_{3}=\text { Knowledge; Skill and Attitude respectively. }
$$

Regression analysis was employed to provide the formula for finding the equation of the line of best fit for our model. According to Ojamieruaye and Oaikhenan; $(2001 ; 53)$ regression theory postulates that there exist a stochastic relationship between a variable $\mathrm{Y}$ and a set of other variables (say, $\mathrm{X}_{1} ; \mathrm{X}_{2} ; \ldots \ldots \ldots \ldots \mathrm{X}_{\mathrm{k}}$ ). In other words, $\mathrm{Y}$ referred to as the dependent or explained variable depends on other observed variables, $\left(\mathrm{X}_{1} ; \mathrm{X}_{2} ; \ldots \ldots \ldots \ldots ; \mathrm{X}_{\mathrm{k}}\right)$ called the explanatory variables, and an unobserved random term usually denoted by U". Thus, the general linear regression model is expressed as follows:

Where:

$$
\begin{gathered}
\mathrm{Y}=\beta_{0}+\beta_{1} \mathrm{X}_{1}+\beta_{2} \mathrm{X}_{2}+\ldots \ldots+\beta_{\mathrm{k}} \mathrm{X}_{\mathrm{k}}+\mathrm{U} \\
\mathrm{Y}=\text { Return on Capital Employed (ROCE) }
\end{gathered}
$$

$\beta_{1} ; \beta_{2} \ldots \ldots \beta_{\mathrm{k}}$ are the parameters (coefficients) of the independent variables of the model;

$\beta_{0}$ is the intercept (i.e. the expected value of $Y$ when all the explanatory variables assume zero as value.

$$
\mathrm{U}=\text { Random disturbance. }
$$

According to Omorokpe [2003:193]; ROCE is the ratio of Profit (returns) to Capital Employed in an accounting entity or firm usually expressed as a percentage. Various measures of profit and capital employed may be used in calculating this ratio. This ratio identifies how much profit the business has made from the capital invested in it. Theoretical literatures suggest that Knowledge impacts positively on ROCE, that the more knowledgeable the employees of a bank are, the better it would be to achieve higher earnings and thus ROCE. Koenig and Membrilla gave insight into how individual knowledge contributes or enhance company knowledge and how this affects the company performance in the management of its capital to earn good returns, vis-à-vis ROCE. Koenig and Membrilla (2008:1) argued that 'the importance of people has become increasing important. Money talks but does not think. Thinking and invention are the assets upon which knowledge work. There is no longer just a physical employee; there is a knowledge employee'. This implies that the knowledge of an employee affects and enhances company performance and thus its profits or earning referred to as Return on Capital Employed (ROCE).

Empirical and theoretical evidence also suggest that the skill of an employee of an organization impact positively on the management of the organization and thus, on it's ROCE. This is so because skill is a key driver of innovation and productivity. In particular, management and technological skills are particularly important considering how strategic they impact on productivity.

We also deduced from empirical and theoretical literatures that an employee of an organization with a winning attitude can impact positively on ROCE. According to Udom; [2002:286-287]: a winning attitude is a prerequisite for success in management; a winning attitude is a recipe for managerial effectiveness. This suggests that Managerial effectiveness can only be possible with the choice and placement of people with the right attitude on managerial position. In this way profit or returns or earnings, the key influencing factor of ROCE is maximized. In the light of the above discussion, we specify a model to capture the link between the explanatory variables and how they impact on ROCE. For the purpose of our empirical analysis, we specify below an empirical model to explain the effect of our explanatory variables on ROCE.

$$
\text { ROCE }=\beta_{0}+\beta_{1} \text { know }+\beta_{2} \text { skill }+\beta_{3} \text { attit }+\mathrm{U}
$$

Where:

$$
\text { ROCE }=\text { Return on Capital Employed; }
$$

$$
\begin{gathered}
\text { know }=\text { Knowledge; skill }=\text { Skill } ; \text { and attit }=\text { Attitude } \\
U=\text { Random disturbance; }
\end{gathered}
$$




$$
\beta_{1} ; \beta_{2} ; \beta_{3} \text { are the model parameters. }
$$

The apriori expectations with respect to sign are:

$$
\beta_{0}><0 ; \beta_{1}>0 ; \beta_{2}>0 \text { and } \beta_{3}>0
$$

\section{Analysis of Empirical Results}

\subsection{Pearson Correlation Coefficients of Variables}

Pearson correlation coefficient matrix of all the variables, Knowledge, Skill, Attitude and Return on Capital Employed (ROCE) are shown in Table 2. The explanatory variables Knowledge, Skill, Attitude, and the explained variable ROCE exhibit moderately high Pearson correlation coefficients between one another in the correlation matrix . Most outstandingly are the coefficient of correlation between Knowledge and Attitude which stood at .8677. Also the coefficient of correlation between knowledge and skill was .7896; Knowledge and ROCE stood at .6703 and Attitude and ROCE stood at .6054. These statistics suggests the existence of a strong linear relationship between the variables. However, the correlation matrix revealed one relatively low coefficient of correlation, that between Return on Capital Employed [ROCE] and Skill which was .4614. Generally, the other variables recorded moderately high coefficients of correlation, which range from 0.60 to 0.86 . The implication of these results is that the job knowledge of an employee is positively correlated with his skill level. On the other hand, his skill is positively correlated with a winning or right attitude towards the job. Better put, the right attitude of an employee towards his job proliferate his skills. Resultantly, these intrinsic values in the head of an employee enable him display high level of proficiency at work place and thus efficient capital management abilities.

Judging from these relatively high coefficients of correlation between each of the variables and particularly between the dependent and independent variables, we reject the Null hypothesis of no relationship and accept the Alternative hypothesis of a relationship. We therefore conclude that our Competence-based predictor variables, Knowledge, Skill and Attitude have strong linear relationship with ROCE, indicating that they are relevant to the management of bank capital in the banking Industry.

\subsection{Analysis of Regression Result}

In this empirical estimation, Return on Capital Employed [ROCE] was regressed on Competence predictors Knowledge, Skill and Attitude. The regression results were analyzed using the t-test coefficients which attests to the significance of each of the independent variables, the coefficient of determination, otherwise referred to as adjusted $\mathrm{R}$ square $\left(\mathrm{R}^{2}\right)$ which measures the proportion of variation explained by the independent variables in the regression model and the F-statistics of the ANOVA report which attests to the overall significance of the model. These empirical results which were employed to explain and test the Null hypothesis formulated are presented in Tables 3, 4 and 5. For ease of reference, we reiterate the null hypothesis as follows:

Ho: There is no relationship between Return on Capital Employed [ROCE] and Knowledge, Skill and Attitude with respect to bank capital management in Nigeria.

The empirical results indicate that Knowledge impacted positively on ROCE. The positive sign of the Knowledge coefficient is in conformity with apriori expectation which explains that basic knowledge is required and important in terms of producing goods and services efficiently; that knowledge brings about product innovation and that helps the Management of organizations optimize efficiency in all ramifications to achieve good returns. In relation to our focus in this study, it means Knowledge enhances bank capital management towards achieving appreciable returns. However, Knowledge coefficient of 1.321 failed the test of statistical significance at all significant levels. The result thus appears to suggest that Knowledge is not relevant in formulating policies that can affect ROCE. This negates apriori expectation but evidently show that some bank employees in the banks under investigation are deficient in the fundamental knowledge required to efficiently manage bank capital.

The coefficient of Skill variable from the empirical results showed a negative sign. The empirical evidence with respect to this variable fails the test of significance. These results may be reflecting the negative impact of the recruitment strategy that undermined professionalism that has been the practice particularly from the 1980s in Nigeria where bank employees are drawn from all academic disciplines. The results may be suggesting that engaging bank employees devoid of fundamental banking or financial or related discipline training impacted negatively on the skill level of the employees of our sampled banks and with particular reference to bank capital management and consequently on ROCE. The variable thus failed the test of statistical significance as the t-statistics of -.717 shows. Based on this empirical finding, it casts fear as to whether Skill can be considered as being relevant to policies that are formulated to affect ROCE, which again negates apriori expectation. 
However, the coefficient of the Attitude variable appears to suggest that employee attitude to work positively impacted on the dependent variable (ROCE) in banks sampled. With a coefficient of .825 the positive sign conforms to apriori expectation as it suggests that an employee right attitude to work could impact positively on his general performance and indeed enhance Return on Capital Employed (ROCE). However, the variable failed the test of statistical significance at all significant levels and this cast doubt on its relevance to policies that are formulated to affect ROCE.

The coefficient of determination, the R-squared which gives information about the goodness of fit of the model indicate .358 meaning that the explanatory variables namely, Knowledge, Skill and Attitude accounted for only $35.8 \%$ of the systematic variation in ROCE. This means that approximately $36 \%$ of ROCE was explained by the independent variables and that the remaining sixty four percent was explained by unknown variables or inherent variability. The F-statistics coefficient of the Analysis of Variance (ANOVA) which attest to the overall significance of the model indicate 4.15 which shows that the overall estimated model failed the test of overall significance.

Generally, the regression analysis results are poor, appearing to suggest that Knowledge Skill and Attitude are more or less not too relevant in formulating policies that would affect efficient management of bank capital to generate adequate returns (ROCE). This truly negates apriori expectation but evidently shows that some employees in the banks under investigation do not have the fundamental knowledge and required skills to efficiently manage bank capital. This fact relatively holds true considering the recruitment strategy of a workforce drawn from all academic disciplines that are largely deficient in banking knowledge and skills and charged with the responsibility of handling specialised or professional banking tasks. It somewhat explained the reason why some banks in Nigeria operated on negative shareholder's fund before CBN rescue mission in 2009, meaning that a good proportion of middle and top management employees of such banks may have lacked the necessary knowledge and skill required to manage their bank capital effectively.

\section{Summary, Conclusion and Recommendations}

In business circles in the past few decades, the concept of organizational performance were attributed to the size and the divisions of the organization and also to concepts and processes such as Reengineering, Total Quality Management [TQM], Net-work building, Vertical Integration et cetera. Competence-based approach to performance is a new strategy aimed at establishing that the human attributes is the most valuable input into any performance strategy of organizations and even Nations The study provides additional evidences suggesting that core Competences namely; knowledge, skill and attitude are important factors that determine and predict outstanding performance of employees in an organization and that they obviously impact positively on bank capital management in the banking industry in Nigeria. We used the Correlation Analysis and Regression analysis to estimate the impact of Competence-based predictors namely, Knowledge, Skill and Attitude on Return on Capital Employed (ROCE), the variable that measures how effective bank capital has been utilized. Data were computed using the Statistical Package for Social Science [SPSS], Version 16.0 for Windows.

In our results and findings, most of the Pearson Correlation coefficients in the coefficient matrix obtained from our empirical estimation stood above .6000 , except for one, the coefficient between ROCE and Skill which stood at 4614 . This outstanding result displayed by the correlation coefficients is a strong indication of a significant linear relationship between the variables. Since correlation analysis measures the strength of the relationship between variables, these very high correlation coefficients are clear proof that the null hypothesis should be rejected. We therefore conclude that a relationship exists between competence-based predictors; Knowledge, Skill and Attitude and ROCE, the measure of the effectiveness of bank capital utilization and management in Nigeria.

However, the results from the Regression model estimation of Return on Capital Employed (ROCE) regressed on Knowledge, Skill and Attitude were poor. The F-statistics coefficient of the Analysis of Variance (ANOVA) which attest to the overall significance of the model indicate 4.15 which shows that the overall estimated model failed the test of overall significance. Based on this empirical finding, it casts fear as to whether the independent variables, namely Knowledge, Skill and Attitude can be considered as being relevant to policies that are formulated to affect ROCE. Absolutely, these findings negate apriori expectation.

While Pearson correlation coefficients showed strong linear relationship between the dependent and independent variable, the empirical results of the regression estimation indicate a rather weak relationship between the dependent variable, Return on Capital Employed (ROCE) and Knowledge, Skills and Attitude. In order to maximize the utilization of bank capital funds in the Nigerian banking industry and positively achieve the goals of recapitalization exercise, we put forward some policy recommendations. Most importantly, we emphasize the need to invest in 
human capital as it offers the highest returns in terms of increasing organizational performance and managerial efficiency because that would enhance the level of knowledge, skills and behavioural capabilities of the employees.

In our view, the continuous increase of bank Capital base is not synonymous to effective management and does not guarantee continuous stability of banks considering the fact that earlier increments in bank Capital were quickly swallowed up partly by the harsh economic situation, vis a vis, hyper inflation and partly by incompetence of banks Management team. The safe currency is 'Competence'. It ensures the safety of the organization, the Bank and its going concern. The post recapitalization era in Nigeria has witnessed further merger and acquisition and buyout of some banks. This is a clear indication that high Capital base does not necessarily predict performance or sustainability of the resultant competitiveness among banks. The Nigeria government and the Management of banks should give priority to and emphasize Competence in order to drive performance and achieved the goals and objectives that the re-capitalization exercise seek to achieved. Again, investing in human capital and particularly, recruiting and matching employees with right academic qualifications and thus right competences with job task offer the highest return in terms of increasing performance. Banking as a skillful profession require employees with right banking training because that leads to acquiring needed banking knowledge to meet job targets, improves skills and ethical attitude or culture that leads to the attainment of target oriented tasks. This improves performance, generates more benefits and increases return on capital (ROCE) for the Banks. It is a better strategy than focusing on astronomical Capital base which if critically viewed may be regarded as 'idle cash' with minimal yields.

\section{References}

Armstrong M. (1991). A handbook of Personnel Management Practice. London: Kogan Page Ltd., pp.339-469.

Becker G. S. (2001). Talking Human Capital with Gary S. Becker Learning in the New Economy, Cited in Knights D and Wilmoth H (2007). Spring. [Online] Available: www.linezine.com

Boyatzis R.E. (1982). The Competent Manager, a model for effective Performance. New York: John Wiley and sons.

Homer M. (2004, April). Competence Management - how to approach it and the pitfalls to watch out for. The Matchett Group. [Online] Available: http://www.training reference.co.uk/

Jessup G. (1989). The emerging model of vocational education and training. Infed. [Online] Available: http://www.ifed.org/biblio/bcomp.htm.ine

Koenig U., \& Membrillo A. (2008). Impact of Individual knowledge on the Increase of Sustainable Intellectual Capital of organization. A Systematic Approach.

Lynch R. (1997). Corporate Strategy. London: Pitman Publishing.

Micklethwait J., \& Wooldridge A. (1994). The Witch Doctors: What the Management Gurus are saying, why it matters and how to make sense of it. London: Cambridge University Press.

Ojameruaye E. O., \& Oaikhenan H. E. (2001). A first course in Econometrics. Benin City: H. Henans Universal Services.

Omorokpe R. O. (2003). Dictionary of Financial Accounting Terms. Benin City: Mindex Publishing.

Raye and Watter. (2003). Competence Management Strategies (CMS). A future concept in Competence Management for Knowledge-Based Organization. Goteborg: Department of Information.

Sanchez R. (2002). Understanding Competence-based Management. Identifying and managing five modes of competence. Journal of Business Research, 57, 518-532

Smith M. K. (1996). Competence and Competency. Infed. [Online] Available: http://www.infed.org/biblio/b-comp.htm

Wikipedia, the free encyclopedia: Core Competency. [Online] Available: http://en.wikipedia.org/wiki/Core 
Table 1. Data for competence-based predictors, knowledge, skill and attitude

\begin{tabular}{|c|c|c|c|c|c|c|}
\hline \multirow[t]{2}{*}{ Banks } & \multirow{2}{*}{$\begin{array}{l}\text { Questionnaire } \\
\text { Administered }\end{array}$} & \multirow{2}{*}{$\begin{array}{l}\text { Questionnaire } \\
\text { Returned }\end{array}$} & \multirow{2}{*}{$\begin{array}{l}\text { Percentage } \\
\text { of returned } \\
\text { Questionnaire }\end{array}$} & \multicolumn{3}{|c|}{ Mean Scores } \\
\hline & & & & Knowledge & Skill & Attitude \\
\hline Access Bank & 30 & 25 & $83.33 \%$ & 35 & 50 & 50 \\
\hline Afri Bank & 30 & 22 & $73.33 \%$ & 39 & 54 & 48 \\
\hline Diamond Bk & 30 & 25 & $83.33 \%$ & 40 & 44 & 40 \\
\hline Eco Bank & 30 & 25 & $83.33 \%$ & 60 & 55 & 65 \\
\hline Fidelity Bk & 30 & 20 & $66.66 \%$ & 32 & 34 & 30 \\
\hline First Bk & 30 & 25 & $83.33 \%$ & 65 & 70 & 64 \\
\hline FCMB & 30 & 25 & $83.33 \%$ & 48 & 60 & 55 \\
\hline First Inland & 30 & 24 & $80.00 \%$ & 31 & 30 & 34 \\
\hline GT Bank & 30 & 24 & $80.00 \%$ & 60 & 52 & 53 \\
\hline Sterling Bank & 30 & 25 & $83.33 \%$ & 55 & 65 & 56 \\
\hline IBTC Bank & 30 & 22 & $73.33 \%$ & 50 & 42 & 62 \\
\hline Keystone Bk & 30 & 17 & $56.66 \%$ & 46 & 38 & 40 \\
\hline Skye Bank & 30 & 20 & $66.66 \%$ & 30 & 32 & 35 \\
\hline Union Bank & 30 & 23 & $76.66 \%$ & 58 & 62 & 68 \\
\hline UBA & 30 & 24 & $80.00 \%$ & 50 & 56 & 52 \\
\hline Unity Bank & 30 & 18 & $60.00 \%$ & 32 & 30 & 34 \\
\hline Wema Bank & 30 & 20 & $66.66 \%$ & 59 & 60 & 50 \\
\hline Zenith Bank & 30 & 25 & $83.33 \%$ & 68 & 55 & 70 \\
\hline Total & 540 & 409 & $75.74 \%$ & & & \\
\hline
\end{tabular}

Sources: Researcher's, computation based on questionnaire administered; 2012.

Table 2. Estimated correlation matrix of variables

\begin{tabular}{lllll}
\hline Variables & Skill & Attitude & Knowledge & ROCE \\
\hline Skill & 1 & & & \\
Attitude & .7929 & 1 & & \\
Knowledge & .7896 & .8677 & 1 & 1 \\
ROCE & .4614 & .6054 & .6703 & 1 \\
\hline
\end{tabular}

Source: Regression Analysis Report using SPSS Version 16.0 for Windows; 2012

Table 3. Model summary

\begin{tabular}{llllll}
\hline Model & R & R. squared & Adjusted R Squared & $\begin{array}{l}\text { Std Error of the } \\
\text { Estimate }\end{array}$ & $\begin{array}{l}\text { Durbin } \\
\text { Watson }\end{array}$ \\
\hline 1 & $.686(\mathrm{a})$ & .471 & .358 & 6.227 & 2.543 \\
\hline
\end{tabular}

a. Predictor (constant), attitude, skill, knowledge

b. Dependent variable: ROCE

Source: Regression Analysis Report using SPSS Version 16.0 for Windows; 2012 
Table 4. ANOVA (b)

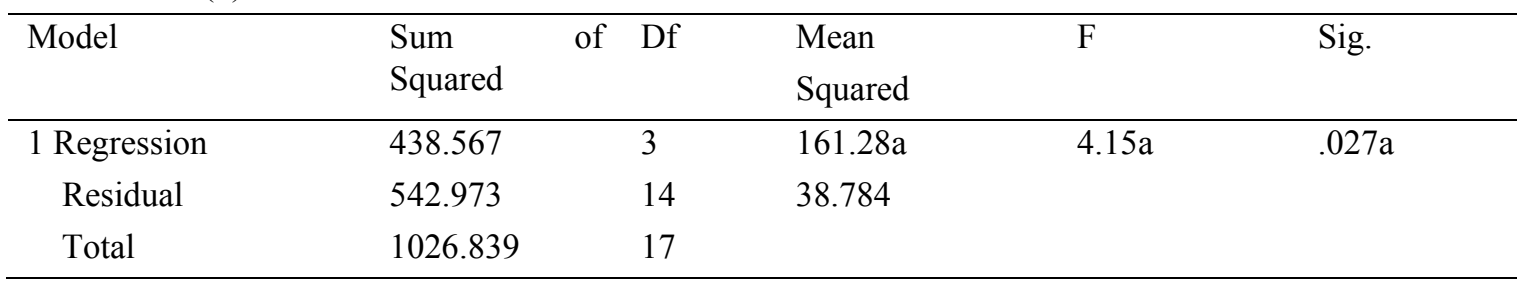

a. predictors (constant) attitude, skill, knowledge

b. dependent variable: ROCE

Source: Regression Analysis Report using SPSS Version 16.0 for Windows; 2012

Table 5. Coefficients (a)

\begin{tabular}{|c|c|c|c|c|c|c|c|}
\hline \multirow[t]{3}{*}{ Model } & \multicolumn{2}{|c|}{$\begin{array}{l}\text { Unstandardized } \\
\text { coefficient }\end{array}$} & \multirow{3}{*}{$\begin{array}{l}\text { standardized } \\
\text { coefficient } \\
\text { Beta }\end{array}$} & \multirow[t]{3}{*}{$\mathrm{T}$} & \multirow[t]{3}{*}{ Sig. } & \multicolumn{2}{|c|}{$\begin{array}{l}95 \% \text { Confidence interval } \\
\text { for } \mathrm{B}\end{array}$} \\
\hline & $\mathrm{B}$ & Std Error & & & & Lower & Upper Band \\
\hline & & & & & & Band & \\
\hline 1 (constant & -6.927 & 6.616 & & -1.047 & .313 & -21.116 & 7.262 \\
\hline Knowledge & .335 & .254 & .547 & 1.321 & .208 & -.209 & .879 \\
\hline Skill & -.147 & .206 & -.239 & -.717 & .485 & -.588 & .293 \\
\hline Attitude & .223 & .271 & .347 & .825 & .423 & -.357 & .804 \\
\hline
\end{tabular}

Dependent variable ROCE

Source: Regression Analysis Report using SPSS Version 16.0 for Windows; 2012 